\title{
CRIMINALIDADE VIOLENTA: POR UMA NOVA PERSPECTIVA DE ANÁLISE
}

\author{
Luís Antonio Machado da Silva \\ Instituto Universitário de Pesquisas do Rio de Janeiro/ \\ Universidade Federal do Rio de Janeiro
}

\begin{abstract}
RESUMO
O artigo aborda o problema da criminalidade violenta urbana no Brasil após a década de setenta, procurando apresentar uma nova perspectiva de análise. Seu argumento é que as interpretações correntes, que vinculam o aumento da criminalidade, especialmente a organizada, à crise institucional são inadequadas, pois não consideram a especificidade do problema, tanto do ponto de vista teórico como, e principalmente, do ponto de vista prático. A criminalidade organizada é uma realidade social com lógica própria, até agora não estudada, e que funciona com certa independência em relação a outros problemas e fenômenos sociais, como a "crise do Estado".
\end{abstract}

PALAVRAS-CHAVE: violência urbana; criminalidade organizada; manutenção da ordem pública; exclusão social.

\section{APRESENTAÇÃO}

Nas últimas décadas, as mais variadas manifestações de violência física têm-se colocado na percepção social, com crescente intensidade, como um dos principais problemas da vida nas grandes cidades, gerando muitas explicações, tanto no plano da existência cotidiana, quanto no da interpretação sociológica. Consideradas globalmente, elas apresentam uma notável homogeneidade, não obstante, como seria de esperar, a ampla variedade de nuances, ênfases temáticas, graus de sofisticação analítica, base empírica etc. De uma maneira geral, esse variado conjunto de explicações constrói uma complexa, mas unívoca, representação da criminalidade violenta no Brasil que se irradia a partir de um núcleo consensual básico: a ameaça à integridade física e à propriedade privada, representada pelo crescimento conjugado do crime comum e do tráfico de drogas, visto este último como a atividade concreta que, direta ou indiretamente, seria a responsável pela crescente organização da criminalidade urbana. Mesmo que este entendimento não corresponda à realidade (ponto que não vem ao caso discutir aqui), trata-se de uma convicção suficientemente arraigada e difundida para colocar na agenda das discussões sobre a conjuntura o tema da ordem pública. É fundamental ressaltar que o que lhe confere especificidade histórica é sua abordagem a partir da experiência social da insegurança individual, física e patrimonial.

De fato, há bastante tempo a unidade construída por aquele tripé - violência, criminalidade comum, narcotráfico — tem sido intensamente vivida como um problema cotidiano, afetando diversos aspectos das condutas rotineiras das populações urbanas no Brasil. Em um primeiro momento, o debate público tratou a questão de uma forma limitada, concentrando-se sobre as dificuldades técnicas, jurídicas e financeiras que incidiam sobre os procedimentos policiais e de administração da justiça, favorecendo a expansão da criminalidade. Isto pode ser visto, por exemplo, no tratamento conferido pela mídia que, salvo em casos excepcionais e durante curtos períodos, continuava circunscrevendo a cobertura da criminalidade às páginas policiais, ao mesmo tempo em que aprimorava a qualidade e aumentava a extensão delas. É verdade que, nadando na contracorrente desta óptica dominante, certos enfoques privilegiavam a crítica à violência policial, politizando o tratamento da questão. Que este não era o ponto de vista dominante fica claro, por exemplo, no insucesso das tentativas de introduzir o problema da cidadania no tratamento dos problemas de rotina do sistema prisional e na maneira de conduzir a atividade repressiva contra a criminalidade comum durante o primeiro governo Brizola (1983- 
1986), para citar o exemplo do Rio de Janeiro. Este período pode ser visto como um exemplo da muito difundida recusa - neste caso, ativa e não meramente implícita - de politização deste problema $^{1}$. De qualquer forma, deve-se notar que, ao basearem o argumento no caráter de classe dos aparelhos de Estado, os críticos da violência policial mantinham a ênfase nas disfunções do aparelho repressivo e, além do mais, tornavamnas conseqüências necessárias, previsíveis e, portanto, insuperáveis, da existência mesma destas instituições.

Nos últimos anos, o problema da criminalidade violenta parece vir aos poucos se aproximando de um debate menos limitado, que situa o tema da manutenção da ordem pública como parte da questão mais ampla da democracia brasileira. Creio que um marco provável para esta inflexão foi a influência dos aspectos policiais da crise que desembocou no fim do governo de Fernando Collor. De qualquer forma, mesmo que este não seja o caso, é certo que a dimensão política da questão assomou à percepção social com inquestionável intensidade nos últimos anos, a partir de uma série de dramáticos incidentes que expuseram, seja o envolvimento de policiais com grupos de extermínio e com o tráfico de drogas (o "massacre da Candelária", a "chacina de Vigário Geral" etc.), seja a crueldade dos métodos oficiais de atuação da polícia (o "massacre de Carandiru", por exemplo). Acontecimentos como estes não podiam ficar restritos, como antes, às explicações limitadas às dificuldades de administrar procedimentos rotineiros de vigilância e controle, ou às referências genéricas ao caráter intrinsecamente autoritário e violento do próprio funcionamento das agências estatais. As críticas à moralidade vigente entre os membros das forças policiais e à violência inscrita na própria cultura organizacional dos órgãos de repressão, suscitadas por aqueles episódios, passaram a fazer parte da agenda de debate sobre a extensão da cidadania e a democratização das relações sociais. Assim ampliado, o entendimento do problema da criminalidade incorporou, ainda que de uma forma tímida, a limitação dos meca-

1 Cumpre mencionar, de passagem, que este trabalho está marcado por minha experiência de vida no Rio de Janeiro. Apesar disso, como esta cidade pode ser considerada um caso exemplar ou "típico" dos fenômenos aqui tratados, creio que a reflexão desenvolvida pode ser generalizada, pelo menos para o conjunto das metrópoles brasileiras. nismos institucionais (e não apenas dos recursos técnicos e financeiros) de controle social, reduzindo o caráter unilateral das críticas à arbitrariedade, violência e corrupção dos policiais e abrindo espaço a propostas de colaboração de outros atores na manutenção da ordem.

Os movimentos de policiais civis e militares reivindicando melhores salários e, em certos casos, também melhores condições de trabalho que se espalharam por todo o Brasil a partir de Belo Horizonte, vieram reforçar esta tendência de politização do tema. Pondo em questão as condições de vida de um segmento do funcionalismo público, eles conduziram a atenção para a associação entre o "desmonte" do Estado, o esgarçamento da ordem pública, a expansão da criminalidade e a generalização do recurso à violência.

Estes rápidos comentários têm apenas a intenção de introduzir o pressuposto básico do presente texto: nas últimas décadas, a partir de uma dramática intensificação da experiência de insegurança pessoal, vem se consolidando uma compreensão muito particular dos problemas de manutenção da ordem pública. Sua característica básica é a ênfase nos inúmeros aspectos que configuram a fragilidade das agências de controle e repressão ao crime. Porém, não se trata mais de um simples "caso de polícia”, isto é, estritamente ligado às práticas da corporação, nem de um mero problema de eficiência dos aparelhos repressivos, passando a envolver cada vez mais o debate sobre a expansão da cidadania. $\mathrm{O}$ foco do debate se amplia, de modo a incorporar de maneira mais direta a relação entre democratização - mais especificamente, garantia universal de direitos civis - e eficácia policial.

Entretanto, ao mesmo tempo em que faz avançar o debate sobre uma série de questões relacionadas à segurança das populações urbanas, esta perspectiva continua inviabilizando o entendimento das condutas dos próprios criminosos, os agentes ativos da experiência de insegurança pessoal. $\mathrm{Na}$ realidade, na medida em que o crime - e, mais especificamente, o crime violento organizado aparece como resultado da ineficácia da ação repressiva, ainda que no quadro ampliado que acabo de mencionar, segue-se como conseqüência lógica o suposto de que ele poderia ser cancelado, inviabilizado ou pelo menos reduzido a proporções toleráveis pela manipulação de variáveis contextuais. Uma vez que a construção de suas ações pelos próprios criminosos deixa de ser considerada, o problema da criminalidade desaparece, 
convertendo-se numa questão de institution building que envolve as agências da ordem, suas relações com a sociedade civil e a formulação de políticas democráticas de segurança pública.

Dito de outra forma, a lógica do mundo da ordem logra uma nova vitória de Pirro: a compreensão de seu funcionamento se expande, incorporando novos aspectos antes desconsiderados, na exata medida em que a desordem é negada e reduzida à mera ausência da ordem.

O presente trabalho contém um comentário metodológico que procura lidar com esta dificuldade específica da explicação dominante, sem pretender substituí-la ou negar que ela versa sobre questões de importância fundamental. Trata-se, antes, de um diálogo que objetiva apenas argumentar a favor da plausibilidade e relevância de um ponto de vista sobre a organização social da violência contemporânea nas grandes cidades brasileiras que toma como ponto de partida a criminalidade comum violenta.

Não desejo, portanto, ultrapassar a mencionada experiência de insegurança - até porque, sem levá-la muito a sério, não é possível compreender o que se passa na vida urbana contemporânea -, nem apresentar uma interpretação "melhor" para os problemas de manutenção da ordem pública ou da violência urbana. Penso apenas que a perspectiva que sugiro é capaz de revelar e pôr em discussão uma tendência que a explicação dominante não tem condições de perceber: a transformação da violência, de meio socialmente regulado e minimizado de obtenção de interesses, no centro de um padrão de sociabilidade em formação. Dada a relevância do problema, considero urgente que seu desconhecimento dê lugar a um debate aberto e direto, pois trata-se justamente daquilo que confere especificidade histórica à violência contemporânea nas grandes cidades, tornando-a um objeto sociológico singular e um problema social muito mais complexo e profundo do que sua apreensão atual faz crer.

É necessário enfatizar que a reflexão aqui desenvolvida é preliminar e incompleta. Incompleta, porque não tenho condições pessoais de resolver os enormes problemas que aponto adiante. Para que se possa aquilatar seu escopo, basta mencionar que, como se verá a seguir, eles incidem sobre o significado cultural do individualismo contemporâneo e, em última instância, conduzem ao questionamento da relação de alteridade como condição universal e necessária da sociabilidade. E preliminar, pois se o conhecimento empírico da criminalidade violenta produzido desde a perspectiva dominante é reconhecidamente superficial e fragmentar, ele é ainda mais incipiente do ponto de vista aqui proposto - situação que, sem dúvida, só pode ser alterada pela sua explicitação, debate e eventual incorporação à pesquisa sociológica ${ }^{2}$.

\section{A EXPLICAÇÃO DOMINANTE: UMA CRÍ- TICA}

A questão da criminalidade violenta nas grandes cidades é um dos eixos centrais de um quadro de referência que opõe dois momentos, em uma periodização cujo marco é quase sempre a virada para os anos 70. Ela se baseia na percepção da diferença entre o passado, quando o crime era vivido como um problema menos angustiante, e o presente, período em que a criminalidade se torna progressivamente mais violenta e organizada. $\mathrm{Ou}$ seja, produz-se um corte temporal em que o passado se caracterizaria, não pela ausência de condutas criminosas, mas por seu encapsulamento enquanto ações isoladas e intersticiais, e o presente corresponderia a um momento em que essas práticas se organizam em empreendimentos coletivos e permanentes, evidenciando dificuldades inusitadas de manutenção da ordem pública que tornam dramaticamente insegura a vida cotidiana. Pode-se dizer, portanto, que o núcleo da percepção social destas questões é o crime comum organizado. É evidente que a existência da criminalidade difusa não deixa de ser reconhecida; mas a diferença é que agora o crime passa a ter uma "cara" - uma estrutura, um agente responsável.

As populações urbanas parecem considerar que a delinqüência tradicional correspondia a atividades criminais realizadas por "pessoas comuns" que cometiam deslizes de gravidade variável. Neste sentido, ela se distingue do crime organizado como empreendimento permanente e baseado na ameaça de violência física, que dependeria de princípios de orientação da conduta radicalmente diferentes. Ou seja, organizados, os criminosos destacam-se da coletividade.

Estou sugerindo que a percepção social difusa

2 Considero que o texto mais rico e abrangente sobre 0 mundo da criminalidade comum é uma obra de fiç̧ão: LINS, 1997; 0 que pode servir de ilustração sobre a carência de estudos sociológicos que discutam a formação da ação dos criminosos. 
possui sensibilidade suficiente para dar-se conta de uma inflexão, marcada pelo surgimento de um novo ator coletivo que altera as condições de reprodução da ordem pública. Entretanto, sua expressão cognitiva consciente, tal como surge no debate público e na maioria das análises acadêmicas, não tem sido capaz de captar esta profunda transformação qualitativa - ou, na melhor das hipóteses, só o faz de maneira indireta.

Assim é que, neste plano, a explicação do desenvolvimento do crime organizado põe em questão, nos termos mais imediatos, a relação entre dois agentes: de um lado, os próprios criminosos $\mathrm{e}$, de outro, os policiais enquanto encarregados diretos da atividade institucional de controle e repressão. Entretanto, não parece exagero sugerir que, já neste nível mais concreto, praticamente todo o peso da lógica explicativa que tenta apreender esta relação recai sobre as condições e o modo de funcionamento do aparelho repressivo. Começando com a análise da polícia, mas raramente restringindo-se a ela, a explicação enfatiza a crise moral e de autoridade das instituições responsáveis pelo controle social e administração da Justiça, causa de uma incapacidade radical de cumprimento de suas atribuições, a qual se manifesta sob as mais variadas formas de impunidade, corrupção e tratamento discriminatório das populações mais pobres. O resultado final é a "criminalização" da própria polícia, a desproteção das camadas populares e o estímulo ao desenvolvimento do crime organizado.

De passagem, note-se que este é o nível mais concreto e tópico de uma explicação cujo sentido profundo é extraído do reconhecimento de que ela trata da expressão localizada de uma crise institucional que é antes política que econômica. De fato, embora seja recorrente a menção à penúria das agências governamentais, em uma linha de raciocínio cada vez mais generalizadora que a remete à crise fiscal e à reconversão da economia, estas causas de natureza econômico-financeira têm antes o estatuto de variáveis intervenientes na explicação. Sua característica mais abrangente que pode perfeitamente passar como descrição típica da "estrutura da conjuntura" atual — é a incapacidade generalizada de atuação do conjunto das agências do Estado: a ineficiência e a desmoralização interna do aparelho policial seriam parte de uma crise política que afeta toda a estrutura do Estado e sua relação com a sociedade.

Esta descrição, obviamente muito esquemática e superficial, não pretende captar a riqueza e variedade das análises, mas apenas expor seu centro nevrálgico no que diz respeito à concepção dominante sobre a criminalidade nas grandes cidades. A intenção é identificar o que considero como o nexo causal básico da interpretação da relação entre ordem pública e criminalidade violenta na atualidade: de um lado, como variável independente, uma profunda crise de autoridade, provocando a ineficiência das agências estatais e o encolhimento do Estado; de outro, a variável dependente a ser explicada: o crescimento do crime organizado nos espaços em que a atividade regulatória e as políticas substantivas do Estado não conseguem preencher ${ }^{3}$.

Incidentalmente, podem ser notadas importantes mudanças nas imagens da pobreza decorrentes desta explicação. Os pobres transformam-se em vítimas, deserdados dos benefícios materiais da cidadania e membros periféricos de uma sociedade que o Estado não abarca inteiramente. Nem "classe perigosa" (papel que passa a ser reservado ao crime organizado) nem "sujeito" de sua própria história: simplesmente vítimas de uma ausência, a do Estado. A este respeito, é ocioso lembrar as inúmeras variantes conceptuais que convergem para a idéia básica de "ausência do Estado".

Estas observações não podem ser aprofundadas no presente texto, mas vale salientar que elas apontam para o aspecto espacial da explicação mencionada: a ineficiência do Estado é percebida como não apenas social, mas também territorialmente seletiva, afetando de maneira mais intensa as áreas pobres das cidades, locais privilegiados do crime organizado. É claro que não se alteram as tradicionais avaliações sobre a forma urbana, agora sustentadas em novas bases: as favelas, que tipificam na percepção social as áreas degradadas,

\footnotetext{
3 Dentre a miríade de possíveis ilustracõos concretas desta lógica explicativa, destaco matéria publicada na revista $\mathrm{V}$ ja de 08/ 09/93, a propósito do episódio conhecido como a "chacina de Vigário Geral", que me parece paradigmática em extensão - 13 páginas, vários autores - e proximidade das análises acadêmicas. Recheada de referências à "falência do Estado", "ausência do Estado", "apodrecimento da polícia" etc., como conclusões sobre a ineficiência dos órgãos públicos (inclusive, mas não apenas da polícia) e seu descaso para com as regiões de moradia da pobreza urbana, a mencionada relação causal ali aparece de forma sintética e explícita: "A ordem desertou a favela [sic][...]. A debandada dos serviços básicos rendeu Vigário Geral aos traficantes" (p. 29).
} 
continuam tão ameaçadoras quanto antes. Mas turvam-se as fronteiras de classe dessa percepção, pois agora elas são perigosas também para os po-bres. Tudo isso expõe uma característica essencial do problema, tal como ele está construído na atualidade: trata-se de uma questão sistêmica geral, cujo sentido não se esgota nos conflitos de classe.

A esta altura deve estar claro que a estrutura do argumento é semelhante ao clássico modelo durkheimiano. Assim, tanto a ineficiência das agências estatais, quanto a organização da criminalidade violenta são descritas e interpretadas segundo o conhecido padrão ordem-desvio, que corresponde ao quadro geral de todo o raciocínio. Em seu núcleo está uma concepção unificada da lógica da vida social e seu corolário, a idéia de que a patologia, quando existe, encontra-se nas características do sistema. Se este modelo tem a vantagem de não tratar o comportamento desviante como uma aberração incompreensível, por outro lado apresenta a desvantagem de não permitir considerar os cursos de ação desviantes, segundo o quadro normativo considerado, como qualitativamente distintos dos demais (pois o desvio é definido como uma desproporção quantitativa, e não um atributo qualitativo).

Mesmo nas versões que preservam a autonomia dos agentes e pretendem concentrar-se nos cursos de ação construídos por eles, o esquema explicativo muda pouco. Resumidamente, elas propõem a recomposição da ordem pública através de uma variedade de negociações visando a expansão da cidadania, isto é, incorporando as demandas de segmentos cada vez mais amplos das populações urbanas, e tornando as práticas das agências estatais social, política e territorialmente mais abrangentes. Aqui, há duas idéias subjacentes que vale a pena mencionar.

A primeira delas é a de que a restauração da ordem pública depende do fortalecimento do Estado mas, ao mesmo tempo, isto só vai ocorrer quando o funcionamento de suas agências for social e espacialmente mais homogêneo e universalista. Ao contrário de interpretações mais antigas, não se trata nem de opor Estado e sociedade, nem de apagar esta diferença. Tratase, antes, de reaproximar um do outro, de modo a eliminar o padrão anti (ou pouco) democrático da interação entre eles que, em última instância, é tido como o responsável pela fratura que ocasiona a dissolução da ordem pública. Considero que este ponto do paradigma explicativo é eticamente defensável e intelectualmente sensato, além de corresponder aos elementos mais gerais de um consenso mínimo, capaz de fundamentar um diálogo fértil entre as muitas posições diferentes que admite.

A segunda idéia é a de que, no longo prazo, este processo de construção democrática é condição suficiente para restaurar a ordem pública, fazendo retornar a condições aceitáveis a margem de insegurança presente no curso da vida cotidiana. Ao contrário do anterior, este é um dos pontos que me parecem mais problemáticos na estrutura da explicação dominante. Ele se baseia na idéia de que, sob condições mais democráticas, melhoraria o desempenho, pelas agências estatais, de suas funções de controle social que, ademais, seriam facilitadas devido ao impacto das tendências democratizantes sobre a reprodução social, reduzindo as pressões econômicas que favorecem a adoção de práticas criminosas. Ou seja, reduzido o espaço de organização da criminalidade, aumentaria o custo de escolher condutas criminosas até o ponto em que estas alternativas seriam descartadas por agentes racionais.

Esta estrutura lógica parece-me duplamente inconsistente. Em primeiro lugar porque, baseando-se no postulado implícito de que a adaptação ao novo contexto é a atitude mais racional, nega a intenção de reter como base da explicação a autonomia de decisão dos agentes: normas institucionalmente garantidas determinariam as escolhas subjetivas, tal como na primeira versão comentada acima. E, em segundo lugar, porque adota dois pesos e duas medidas: enquanto os criminosos se regeriam sempre e apenas pela lógica instrumental, o restante das populações urbanas pode fundamentar suas ações em princípios éticos e morais (os valores ligados à construção da democracia) mesmo sob condições que não os recomendariam como as "melhores escolhas" de curto prazo.

Esta sumária exposição da estrutura lógica da explicação dominante visou demonstrar que, paradoxalmente, o desenvolvimento do crime organizado acaba se tornando uma questão secundária. As formas recentes da criminalidade são reduzidas a uma expressão da crise institucional e se transformam em meros indicadores de sua extensão e profundidade. Ou seja, o emprego crescente da violência e a transformação das condutas criminosas em empreendimentos permanentes são fenômenos apreendidos como meros 
efeitos, simples sintomas da incapacidade das agências de controle social de cumprir satisfatoriamente suas funções. Assim, embora se localize na organização da criminalidade violenta o principal problema de manutenção da ordem pública, a atenção volta, em uma espécie de "efeito boomerang", a concentrar-se não na formação da conduta dos criminosos, mas antes nos processos endógenos de dissolução da ordem.

Não é demais repetir: estamos diante de uma concepção unitária e homogeneizante da vida social. Talvez seja esta perspectiva geral que não deixa perceber que, do ponto de vista de seus conteúdos concretos, a explicação dominante é um pressuposto, mais que uma análise propriamente dita.

Assim, seria absurdo negar que a conjuntura atual das cidades brasileiras se distingue por uma profunda crise institucional e que a organização da criminalidade violenta torna-se cada vez mais ameaçadora. Mas não me parece plausível estabelecer uma relação de dependência causal entre estes dois processos. De fato, mesmo o mais superficial olhar sobre a formação do Estado brasileiro e a constituição da cidadania em nosso país é suficiente para perceber que a ordem pública nas cidades brasileiras jamais foi um modelo de firmeza dos controles sociais ou de seu caráter democrático. E, no entanto, até por volta dos anos 70 não há evidências de que o processo de organização da criminalidade fosse socialmente significativo. Logo, muito embora as dificuldades institucionais possam ser tomadas como uma condição necessária, elas não são suficientes para explicar a organização da criminalidade violenta.

Estou sugerindo que a explicação dominante - por elaboradas que sejam algumas de suas muitas versões concretas -, não é capaz de produzir uma compreensão intelectualmente adequada da criminalidade comum violenta pois, por assim dizer, no meio do caminho a atenção se desvia do objeto. Como procurei demonstrar, a raiz desta dificuldade está no fato de serem reunidos em uma relação de causa e efeito dois processos que são independentes, pelo menos em parte.

Na próxima seção, retomo estes comentários procurando explorar, ainda de uma forma muito embrionária e com intenções simplesmente ilustrativas, as possibilidades analíticas da separação entre crise institucional e organização da criminalidade. Como venho sugerindo, trata-se de postura indispensável para apreender a singularidade do crime violento e sua importância fundamental no quadro da vida urbana contemporânea. Como é óbvio, a condição para um ponto de vista como este é deslocar a atenção do que chamei acima de processos endógenos de dissolução da ordem. Deve ficar claro, entretanto, que esta providência não significa negar a existência deles nem a necessidade premente de intervenções que visem restabelecer e aprimorar as formas de controle social e a legitimidade da autoridade estatal.

No fundo dos comentários que se seguem está uma concepção (muito embrionária, diga-se de passagem) sobre os processos de "desconcentração" da violência física. Como procurei demonstrar, a criminalidade violenta tem sido entendida como uma espécie de caso-limite, derivado do acúmulo de problemas de regulação e controle que, em última instância, remetem à ilegitimidade do Estado. Pressionada pela premência de intervenções práticas sobre o aparato institucional, a explicação dominante tende a concentrar a atenção sobre o que chamei acima de processos endógenos de dissolução da ordem.

Considero que, embora relevante, esta é uma perspectiva limitada. Quando abordada desde um ponto de vista mais abrangente, é pelo menos plausível levantar a hipótese de que a criminalidade violenta organizada pode ser vista como a ponta de um iceberg. Ela indicaria transformações culturais imensamente profundas e a formação de uma sociabilidade radicalmente nova que a teoria social tem muita dificuldade de apreender, na medida em que aponta para uma visão de mundo que lhe é exterior. Evidentemente, não proponho uma reflexão deste teor, mas apenas uma abordagem mais direta e atenta para as tendências de organização da criminalidade violenta, sugerindo que, até o momento, sua compreensão tem sido muito parcial.

\section{UMA NOVA FORMA DE SOCIABILIDADE}

No final da seção anterior foi mencionada a "desconcentração" da violência física. Vale a pena começar indicando brevemente o sentido e as implicações desta referência do ponto de vista do argumento que vem sendo desenvolvido.

A organização extra-estatal da violência costuma ser considerada dentro de uma classificação que tem como limites, de um lado, a "sobrevivência" de formas pré-modernas de dominação (quando a violência privada é legítima) e, de outro, situações em que várias formas de organização da violência ilegítima desembocam em conflitos que 
vão desde seu uso institucionalizado pelo próprio Estado até a guerra civil, revoltas de grupos ou categorias sociais específicas, bolsões territoriais de resistência etc. A base lógica desta classificação - que, apesar de todas as divergências teóricas, é consensual - encontra-se na idéia de um proces-so unívoco de concentraçãodesconcentração, em que este segundo momento (a desconcentração) corresponde a alguma transformação de fundo na estrutura do Estado ${ }^{4}$. Para o presente trabalho, importa considerar uma implicação: a violência "desconcentrada" (privada/ ilegítima) continua orientada para o Estado, mesmo que o objetivo - que pode estar apenas implícito - seja transformar sua estrutura ou assumir seu controle.

É difícil admitir que esta mesma estrutura lógica possa ser aplicada à organização da violência operada pela criminalidade urbana. Assim, as conhecidas referências ao "poder paralelo" ou ao "Estado dentro do Estado" usadas para indicar o domínio de certas áreas pelo crime organizado não passam de simples metáforas para significar a gravidade do problema e indicar o "descaso" das agências estatais. Além do mais, tudo leva a crer que mesmo os setores mais radicais há muito abandonaram as idéias sobre o caráter revolucionário das organizações criminosas ${ }^{5}$. E, no entanto, parece indubitável, primeiro, que se vive na atualidade um momento de desconcentração da violência; segundo, que este processo não corresponde apenas à sua pulverização como meio de conduta de indivíduos isolados movidos pela certeza de impunidade, nem é um simples caso de cristalização de condutas desviantes; e, finalmente, que o ordenamento das relações sociais operado pelos criminosos não pode ser equiparado às formas tradicionais de dominação, seja nas hierarquias

4 Um bom exemplo encontra-se em Weber, que situa a tipologia das cidades como "dominação não legítima" e ao mesmo tempo formula uma definição típico-ideal da cidade ocidental que permitiria lê-la como uma etapa na formação do Estado moderno. (Isto, é claro, na suposição de que os responsáveis pela edição de $\mathrm{E}$ conomia e sociedade tenham sido fieis às intenções do autor.) Cf. WEBER, 1964.

${ }^{5}$ No caso de outros países latino-americanos, nos quais a inserção política e econômica do narcotráfico é diferente, esta questão não pode ser descartada com a mesma simplicidade. Meus comentários restringem-se ao Brasil.

6 É por isso que referências às "máfias do crime organizado" também devem ser vistas como metáforas que apontam para constitutivas das empresas do crime organizado, seja nas relações destas com suas vítimas e com os grupos sociais dominados ${ }^{6}$.

Neste momento, já deve ter ficado claro que venho repetindo o termo "organização" e suas variantes praticamente desde o início do raciocínio. Isto é proposital, pois quero insistir no fato de que estamos diante de fenômenos que dizem respeito a uma forma de vida social organizada, isto é, a um complexo de condutas para cuja formação a ordem pública não entra como referência. Como já salientei, isto significa dizer que, contemporaneamente, a atividade criminal não pode ser reduzida a priori à mera adaptação ao contexto, pois os criminosos não violam nem se rebelam contra o ordenamento estatal: este simplesmente não é elemento significativo do comportamento destes atores. Embora seja difícil falar em uma esfera ética no caso de relações sociais fundadas na violência, este é exatamente o desafio que se coloca para uma compreensão menos parcial do fenômeno: descobrir como os agentes do crime violento formulam as justificativas de seu comportamento e quais os significados culturais que elas expressam.

Observada deste ponto de vista, apesar das informações serem muito esparsas e de qualidade duvidosa, creio ser possível sugerir como hipótese que a criminalidade comum nas áreas urbanas parece ter passado a organizar-se de uma forma muito diferente daquela que a caracterizava até o final dos anos 60 .

Até aquele momento, o exemplo mais típico de organização das condutas ilegais era o jogo do bicho, em relação ao qual a questão da violência se colocava como um problema secundário ou pelo menos limitado. Assim, parece que tanto sua estrutura empresarial quanto sua inserção política seguiram a tradicional lógica familística de formação de clientela. Não há dúvida que, durante o processo de formação do controle unificado do jogo do bicho, tal como o conhecemos atualmente, as disputas por áreas de atuação freqüentemente envolviam o emprego de meios violentos. Entretanto, tudo indica que se tratava de um recurso

a organização do crime, não como uma descrição de sua forma de organizacão. A máfia se estrutura segundo o modelo de lealdade familística, inteiramente ausente do crime violento organizado no Brasil contemporâneo, como será sugerido adiante. Cf. SCHIRAY \& SALAMA, 1994, p.87-93; ver também IANNI, 1972 
tópico, seletivo e restrito a lutas internas de poder conduzidas com um certo cuidado, a fim de evitar atritos maiores com as demais instituições e grupos sociais .

É também útil lembrar que o jogo do bicho só foi "criminalizado" em 1946, muito depois de sua disseminação, e mesmo assim através de uma medida que não visava a atingi-lo, mas aos cassinos. A expansão de seu poder político e econômico deu-se na fase de ilegalidade, mas alimentou-se do profundo enraizamento deste tipo de aposta na cultura popular.

Além do mais, há claros indícios de que o fortalecimento dessas empresas como agentes econômicos e políticos - que, por sinal, foi um processo lento, se comparado à expansão dos empreendimentos do crime violento na atualidade sempre dependeu de um processo de negociação pacífica com os diferentes agentes do ordenamento legal. Finalmente, cumpre notar que o jogo do bicho desenvolveu uma cultura organizacional paternalista e assistencialista, com hierarquias baseadas em laços pessoais de lealdade, e que orientações dessa mesma natureza cimentaram a formação de clientelas externas em cujo tamanho e coesão baseava-se a capacidade de negociação no jogo político.

O jogo do bicho parece, por todas estas razões, ser típico da natureza ambígua e estruturalmente intersticial da organização das atividades ilegais que envolviam o recurso sistemático à violência privada até a virada para os anos 70. Isso já aparece, como é óbvio, no próprio estatuto formal da atividade, uma simples contravenção. Mas o caráter ambíguo pode ser melhor percebido quando se atenta para o fato de que, juntamente com as escolas de samba, o jogo do bicho foi um dos mais importantes canais de incorporação política e cultural das massas populares urbanas - porém, ao mesmo tempo, também foi um dos instrumentos de manutenção de sua subalternidade ao participar ativamente da manutenção do sistema de controle clientelístico (CHINELLI e SILVA, 1993).

A partir dos anos 70, criminosos comuns passam a organizar-se em empreendimentos que se

\footnotetext{
7 É claro que isto não significou o fim do jogo do bicho como atividade, nem alterou de uma hora para outra seu modo de organização. Em que medida ela foi "contaminada" ou está sendo absorvida pela criminalidade violenta organizada é algo difícil de determinar mesmo na forma
}

consolidam com um formato, conteúdo e sentido sócio-cultural marcadamente diferentes ${ }^{7}$. Seu traço mais básico e rotineiro é o recurso universal à violência. Não me refiro aqui a uma eventual "militarização", analogia que poderia ser aventada em razão da rigidez das hierarquias e do uso generalizado de armas. Penso nos próprios modos de interação entre os membros, também fundados na violência física, que impedem a analogia com as corporações militares. As organizações criminosas atuais, embora sejam empreendimentos econômicos altamente lucrativos - no momento, prioritariamente organizados em torno do tráfico de drogas, que entretanto não é uma atividade exclusiva, nem parece ter estado presente nos momentos iniciais —, não são empresas, no sentido de serem compostas de uma hierarquia orientada para fins coletivos. Elas também estão baseadas internamente nos mesmo princípios de subjugação pela força, constituindo-se em uma espécie de amálgama de interesses estritamente individuais, com um sistema hierárquico e códigos de conduta que podem ser sintetizados pela metáfora da "paz armada": todos obedecem porque e enquanto sabem serem mais fracos, a desobediência implicando necessariamente retaliação física. No limite, podese dizer que não há "fins coletivos" nem "subordinação"; todas as formas de colaboração tornamse estritamente técnicas, e só se tornam possíveis pela subjugação que elimina a vontade dos demais participantes como elemento significativo da formação das condutas. Pouco se sabe sobre a natureza desse processo, mas cabe a metáfora da guerra de todos contra todos - com a ressalva de que falta qualquer movimento para minimizá-la.

A experiência demonstra que, apesar de toda a instabilidade, esse modo de organização pode ser permanente e racionalizado como "técnica" individualmente controlada, não sendo, portanto, apesar de toda a sua fluidez, incompatível com a acumulação de poder e bens materiais.

Sendo estas hipóteses aceitáveis ${ }^{8}$, pode-se di-

apenas ilustrativa e exploratória destes comentários. Só é possível dizer que há informações sobre vários conflitos (alguns armados, outros negociados) em torno do controle de espaços (clientelas e territórios) e sobre "fusões" entre empresas de jogo do bicho e empresas ligadas a outras atividades, como o tráfico de drogas.

8 Penso quea pesquisa empírica disponível, embora se oriente por considerações muito distintas, permite tomar estes comentários como mais do que pura especulação abstrata. 
zer que a organização contemporânea da criminalidade corresponde à implantação da violência generalizada como base de um novo ordenamento social, para cujo entendimento os instrumentos conceptuais disponíveis são inadequados. Pessoalmente, considero que um fértil ponto de partida seria retomar a conhecida idéia de um capitalismo aventureiro, repensada pela introdução de dois elementos: a) os participantes não estão colaborando em um empreendimento coletivo: a lógica do crime organizado é a da subjugação pela violência, não a da agregação de interesses ou da solidariedade comunitária; b) não há incompatibilidade com o cálculo de longo prazo, embora no momento sejam inteiramente desconhecidos os fundamentos de valor de uma racionalização da violência física oposta a seu controle e minimização.

\section{COMENTÁRIOS FINAIS}

Da maneira mais direta ao meu alcance, procurei destacar uma tendência presente na conjuntura atual, tomando como ponto de partida e quadro geral de referência a forma pela qual ela está construída na percepção social. Acreditei que, para poder chegar a discuti-la, era preciso iniciar o tratamento do tema indicando o descompasso entre o sentimento de que estamos diante de um complexo de condutas radicalmente novo e uma formulação intelectual que minimiza este caráter inusitado do fundamento de nossa vivência de insegurança pessoal.

Obviamente, não pretendi resumir toda a riqueza das discussões, teóricas e práticas, que as relações entre a organização da criminalidade violenta e a ordem pública tem suscitado. Minha intenção foi esquematizar brevemente a estrutura lógica que articula todo o debate, para indicar os aspectos que julgo responsáveis por aquele descompasso. Neste sentido, tentei desenvolver um argumento dirigido à reconstrução do objeto desde uma perspectiva que esteja mais orientada para focalizar, de maneira autônoma, a dimensão sócio-cultural da criminalidade. A hipótese geral de que as organizações criminosas sejam portadoras de uma visão de mundo em formação, que abala os mais caros valores da civilização ocidental, pode ser assustadora, mas isto não a torna menos plausível.

O escopo de presente texto é, portanto, muito limitado (embora desafie um dos fantasmas maiores de toda a Ciência Social, o etnocentrismo): apenas sugerir que esse ponto de vista é plausível e relevante. Se isto for aceitável, abre-se um imenso campo de trabalho. Sem ter a pretensão de esgotá-lo, desejo apenas indicar duas ordens de questões que precisariam ser resolvidas.

Pelo menos como tendência, o ordenamento social produzido pela criminalidade organizada cancela a relação de alteridade que tem sido pensada como o fundamento da vida coletiva. De fato, se a pesquisa confirmar o acerto dos breves comentários acima apresentados, a interação entre os criminosos e entre estes e suas vítimas ou grupos subordinados baseia-se na negação do outro como igual, reduzindo-o à condição de objeto. Além dos problemas filosóficos que pode significar uma vida social sem intersubjetividade, em termos mais concretos isto põe em questão as formas assumidas pelo individualismo contemporâneo e os quadros de referência que têm sido elaborados para sua análise.

A segunda ordem de questões subjacentes que precisariam ser enfrentadas diz respeito à necessidade de aceitar com mais firmeza do que é convencional as tendências de fragmentação da vida social, renunciando aos raciocínios totalizadores. Todo o argumento aqui desenvolvido está centrado na independência entre os problemas endógenos de manutenção da ordem pública e a organização da criminalidade violenta. Aceito, ele significa que, ao lado das idéias de competição e luta - de valores, de grupos, de padrões institucionalizados de relação social —, é preciso colocar a idéia de contiguidade, ou de um desenvolvimento divergente entre fenômenos que não se combinam.

A conseqüência prática de tudo isto, para as forças sociais envolvidas com o processo de democratização, é que a institucionalização da violência privada é um problema adicional e paralelo ao da crise endógena das relações entre Estado e sociedade no Brasil. O processo de democratização, o debate público de articulação dos interesses dos diferentes segmentos sociais etc. - em suma, a expansão da cidadania — não garante o controle, cancelamento ou superação da criminalidade violenta. Mesmo no cenário mais positivo de aprimoramento do quadro políticoeconômico seremos obrigados a presenciar a institucionalização da criminalidade violenta, pelo menos até que as referências culturais responsáveis pela formação dessas condutas sejam efetivamente compreendidas.

Recebido para publicação em maio de 1999. 
Luís Antonio Machado da Silva (lmachado@nitnet.com.br/lmachado@iuperj.br) é Professor do Instituto Universitário de Pesquisas do Rio de Janeiro (IUPERJ) e da Universidade Federal do Rio de Janeiro (UFRJ).

\section{REFERÊNCIAS BIBLIOGRÁFICAS}

CHINELLI, F. e MACHADO DA SILVA, L.A. 1993. O vazio da ordem: relações políticas e organizacionais entre as escolas de samba e o jogo do bicho. Revista do Rio de Janeiro, $\mathrm{n}^{\circ}$ 1, p. $42-52,1^{\circ}$ sem.

IANNI, F. A. 1972. A Family Business. Kinship and Social Control in Organized Crime. New York : Russel Sage Foundation.
LINS, P. 1997. Cidade de Deus. São Paulo : Companhia das Letras.

SCHIRAY, M. \& SALAMA, P. (orgs.). 1994. Pensar as drogas. Rio de Janeiro : Fórum de Ciência e Cultura-UFRJ/Association Descartes.

WEBER, M. 1964. Economia y Sociedad. Mexico/ Buenos Aires : Fondo de Cultura Económica. Vol. II.

\section{OUTRAS FONTES}

Revista Veja, 8 de setembro de 1993. 